\title{
O TEMPO DE FESTA É SEMPRE
}

Rita de Cássia Amaral ${ }^{\star}$



vida nas cidades frequentemente é apontada como a fonte da maioria dos males sociais como a violência, a pobreza, os desvios comportamentais, as neuroses etc.. $\mathrm{Na}$ cidade os homens se sentiriam solitários, massificados, tratados pelas instituições como meros números, sem identidade pessoal. Na cidade até o tempo perderia o sentido, pois seria sempre vivido como o tempo do trabalho, sendo o descanso dos finais de semana apenas "um intervalo" entre dois períodos de produção, um tempo reservado à reprodução da força de trabalho, e que os trabalhadores não teriam condições de desfrutar como lazer devido à falta de recursos, oportunidades ou mesmo de disposição. Por isso o tempo não faria sentido, apenas passaria, levando consigo a vida dos homens, especialmente se estes homens são pobres, pouco escolarizados, migrantes, com um gosto próprio em relação ao lazer.

Basta, no entanto, nos determos para observar mais atentamente os inúmeros grupos que vivem na cidade para constatarmos que a verdade não é bem essa. Todos os grupos se organizam em torno de atividades e objetivos comuns, muitas vezes lúdicos, que proporcionam não apenas relações sociais mais diretas, mas afetivas (correspondendo às necessidades de sociabilidade, parceria, companhia, enriquecimento da experiência pessoal), como também organizam, de modo sensível, a passagem do tempo. Marcam a passagem do tempo através de idas ao futebol, à praia, aos ensaios das escolas de samba, aos cultos religiosos, através da participação em romarias ou excursões, festas religiosas, bailes, forrós etc.. Todas estas atividades implicam, para uma população pobre, a organização dos indivíduos em termos de seu tempo disponivel e do dinheiro necessário para sua realização, ocupando o pensamento das pessoas de modo significativo e dando sentido ao trabalho (pois é o trabalho que proporciona os

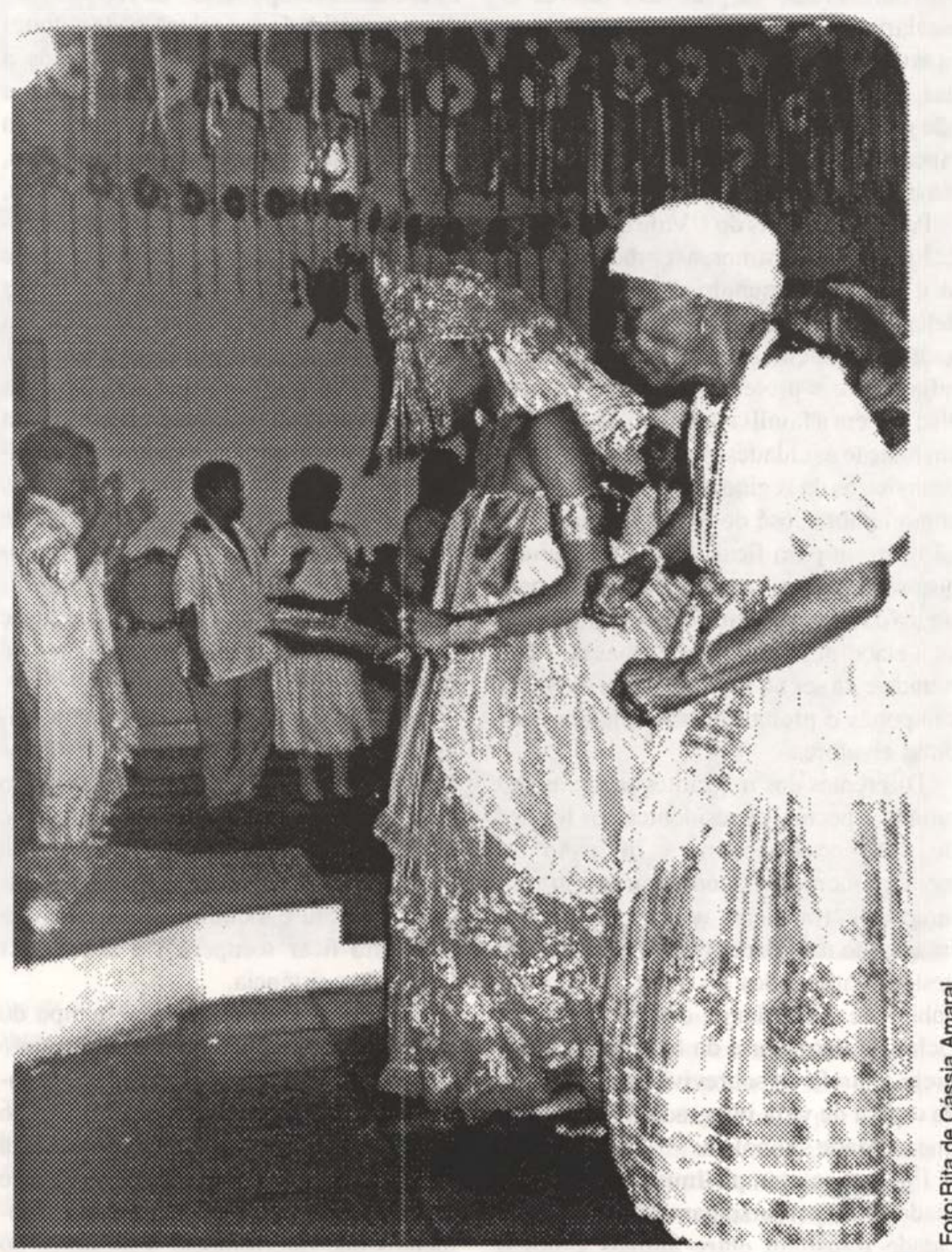

recursos para a sua participação nos grupos) e à própria vida como fonte de prazer.(1)

Um bom exemplo de como a vida pode readquirir seu sentido pela participação num grupo, que através de suas práticas reconstrói relações pessoais e sociais mais "diretas", pode ser dado pelo "povo-desanto", que é como se autodenominam os adeptos do candomblé. Para este grupo, formado majoritariamente por individuos das classes pobres, geralmente migrantes nordestinos (que trouxeram o culto para cá), mulatos, pouco escolarizados, esta religião, mais do que corresponder às necessidadesde transcendência constitui mesmo um estilo de vida, reconhecível por sinais próprios como a linguagem, o jeito, o gosto. Esta participação no candomblé organiza, como veremos e influencia tam- 
bém a vida fora do terreiro.(2)

O candomblé constrói não apenas uma identidade para o filho-de-santo, mas também novas noções de corpo, de espaço e de tempo. No candomblé o corpo do adepto é onde os deuses incorporam e, portanto, muito valorizado. No candomblé os deuses vêm a terra para dançar alegremente, para brincar, para "comer"'as comidas rituais.

Baseado nos mitos dos orixás, que são muito parecidos com os homens, o povode-santo não crê em pecado (3), vivendo portanto plenamente (no presente, porque não se sabe, no candomblé, o que acontecerá depois da morte) sua sensualidade, sua alegria, sua sexualidade, através da dança, da música, do amor, do prazer, do brilho, do excesso, através da Festa. O povo-de-santo é um povo de festa.

A idéia de que a vida é festa marca de modo profundo a visão de mundo do povode-santo e é perceptivel também fora da religião. O sentido da festa, produzido dentro dosterreiros, ultrapassa seus muros e torna-se o elemento que norteia e distingue as escolhas deste grupo em relação aos demais e que aponta de que outros grupos ele pode participar. Assim, o povo-desanto será visto no candomblé mas também nos afoxés, nas escolas de samba, nos pagodes, nos bailes "funk", nos "fundosde-quintais', na capoeira, nos shows de música afro e em várias outras atividades ligadas à festa de um modo ou de outro. A festa marca a passagem do tempo para o povo-de-santo. E isto não é nenhuma novidade. Desde os primeiros estudos, ou autores que investigaram os cultos afrobrasilerios nas diferentes regiões do Brasil afirmavam:

"Chamam-se de candomblé as grandes festas públicas do culto yorubano, qualquer que seja a sua causa'.(4)

Depois deste, vários outros autores perceberam também que a palavra "candomblé" podia ser entendida como sinônimo de festa, ainda que não tenham nunca percebido o caráter estruturante que a festa tem nesta religião. Os autores em geral relatam o grande número de festas realizadas nos terreiros em que fazem as suas pesquisas. Tanto os candomblés baianos, cariocas, paulista etc., como os "xangôs" dePernambuco, o "batuque" doRio Grande do Sul, ou o "tambor-de-mina" do Maranhão realizam, sistematicamente, fes- tas para seus deuses. Em São Paulo, excetuando-se a época da Quaresma, pode-se assistir a inúmeras festas nos finais de semana, sendo possível escolher entre os candomblés de vários ritos, entre vários tipos de festas, diferentes bairros, terreiros, etc..

O "ano litúrgico" do candomblé é organizado de acordo com a realização das festas dos orixás. E é assim que se percebe a passagem do ano. Em janeiro são frequentes as festas de Oxossi, devido ao sincretismo deste orixá com São Sebastião, comemorado a 20 de janeiro. Em abril são feitas as festas de Ogum, em razão de sua associação a São Jorge, comemorado a 24 de abril. Em junho são inúmeras as "Fogueiras de Xangô", sincretizado tanto com São João como com São Pedro. Em agosto acontecem as festas de Obaluaiê, chamadas Olubajés, pelo sincretismo com São Lázaro e São Roque. Em dezembro são feitas as festas das Iabás (orixás femininos) como Oxum, Iemanjá e Iansã (N. Sra. da Candelária, N. Sra. da Conceição e Santa Bárbara, todas comemoradas em dezembro), às quais se juntam Nanã (Sant'Ana) e Obá (Santa Joana D'Arc). Seguindo o preceito do candomblé de que tudo começa por Exu e termina em Oxalá (inclusive oano), também em dezembro se fazem as festas deste orixá, sincretizado com Jesus Cristo, razão a mais para ser festejado durante este mês.

Entre uma festa e outra deste calendário costumam acontecer as "festas individuais' do terreiro, como as Saídas de Iaô (festa de iniciação de um novo adepto ou grupo de adeptos), as Entregas de Decá (festa de conquista do grau de ebomi, o título mais alto do candomblé, que dá direito a alguém de se tornar um pai ou mãe-de-santo), Festas de Obrigação (confirmação da iniciação) e outras como batismos, casamentos, aniversários etc.. Sendo assim, a vida nos terreiros passa a ser organizada em torno da produção dessas festas.

\section{OS CUSTOS DA FESTA}

A produção da festa de condomblé, seja qual for sua razão, mobiliza uma série de recursos simbólicos, sociais e econômicos tanto dentro como fora do terreiro, organizando o grupo em termos de colaboração com dinheiro, trabalho ou as duas coisas. Não podemos esquecer que a maioria do povo-de-santo pertence às classes mais pobres e que o candomblé é uma religião cara: os custos da festa são bastante altos para um grupo tão pobre e, por isso, as despesas devem ser repartidas com os filhos da casa-de-santo. Pede-se ajuda, também, aos clientes e amigos do terreiro, ou mesmo a estranhos, na rua, dando em troca um punhado das pipocas curativas do Obaluaiê, como é costume vermos no centro da cidade. Além disso também é necessário organizar o tempo fora do terreiro para que se possa trabalhar dentro dele, na produção da festa. Faz-se uma espécie de "escala", onde todos participam, sem que seja preciso sobrecarregar alguns. Esta " escala"' leva em consideração os dias de folga de cada adepto, o número de horas disponíveis, as férias, a lua e até mesmo a menstruação das mulheres, que durante o período menstrual não podem trabalhar no terreiro.

Desde a encomenda dos convites (quando há recursos para isto), ou da articulação da rede de informação do povo-de-santo eficientíssima - tem início um trabalhoso processo que inclui não só a coleta de recursos, como já vimos, para a compra dos artigos necessários aos rituais, como ainda uma série de tarefas no terreiro. Deve-se lavar, passar e engomar as roupas de festa e a dos orixás; verificar e consertar as peças que, com os movimentos das danças, se rasgam ou perdem lantejoulas; é preciso polir as insignias dos orixás e as sinetas rituais dos ebomis (os mais velhos, que já receberam o "decá"); durante todo o tempo da preparação das festas é preciso respeitar tabus sexuais e alimentares; participar das matanças (sacrificios de animais) para Exu e outros orixás, depois de percorrer as avícolas procurando os animais mais adequados a cada um deles. Depois do sacrifício é preciso depenar aves, pelar cabritos, separar as partes de cada orixá e cozinhar as carnes, que serão servidas à assistência, no final da festa, no momento chamado de ajeun. Durante todo o tempo destes trabalhos é preciso fazer bules e mais bules de café para os que estão ajudando no terreiro. Sem contar as muitas vezes em que os chefes dos terreiros resolvem dar um " toque"'diferente à festa como, por exemplo, enfeitar a casa com folhas ou flores ou ainda fazer uma roupa 


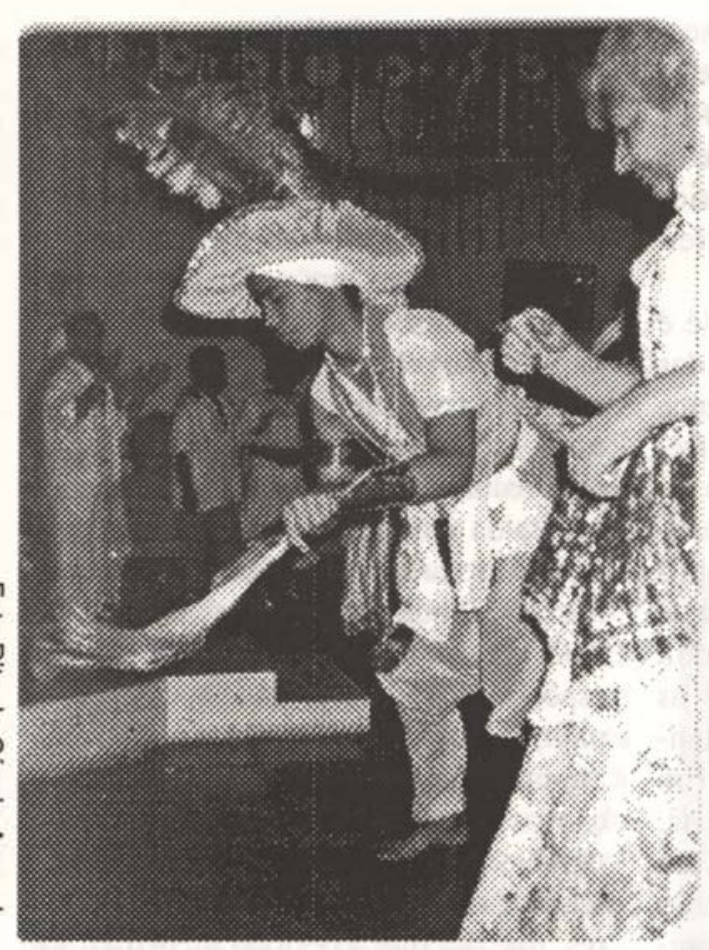

nova para o orixá.

Durante a festa, todos os papéis são vividos intensamente. Tanto os dos homens como os dos orixás. O povo-de-santo se orgulha da beleza de suas roupas, da dança de seus orixás, do sabor da comida que serve, da " qualidade" da assistência, da beleza da música tocada por seus ogãs alabês (tocadores de atabaques). Os ebomis (que já têm 7 anos de iniciados) desfilam orgulhosos com seus brajás (colares que indicam que alguém já é ebomi) que indicam o alto grau de conhecimento do culto. Também a posição que cada indivíduo ocupa na roda-de-santo (conjunto dos que podem dançar num candomblé) indica o tempo-de-santo (de iniciação) de cada individuo, ficando os "mais velhos" no começo e os "mais novos"' no fim. Assim, como o tempo se relaciona ao grau de conhecimento religioso, estar mais perto do "começo" da roda indica maior proximidade do mistério que constitui a religião.

Se a vinda dos deuses a terra para dançar e trazer seu axé implica uma série de tarefas, prescrições e tabus para os que a promovem, por outro lado, para os que a ela assistem, na categoria de convidados, pode representar um verdadeiro espetáculo, com muita música e dança. Este " espetáculo" termina com saborosa refeição, com comidas típicas e bebidas comparti- lhadas com os deuses enquanto se conversa muito, trocam-se informações, endereços, paquera-see trata-se deassuntos pessoais, tais como a possibilidade de conseguir uma consulta com o dentista simpatizante, um emprego no negócio do assistente, uma doação para a iniciação do próximo iaô, para algum reparo no terreiro ou ainda, um programa para o fim-de-semana, que geralmente consiste em assistir outra festa de candomblé, em outra casa. Para alguns adeptos a festa de candomblé chega a ser a única beleza possivel numa vida de privações e tédio:

"Quando eu era criança minha família era muito pobre. Nós não tínhamos nem o que comer, em casa. Então, nos fins-de-semana a gente ia pro candomblé. Lá tinha música, tinha dança, roupas bonitas e brilhantes. Lá tinha comida! O candomblé era a única coisa bonita na minha vida. A única beleza'. (R. de Oxum)

\section{"A ALEGRIA É A PROVA DOS NOVE"}

A participação no candomblé cria vínculos tão significativos entre adeptos que muitos deles comemoram seus aniversários, casamentos, batismos junto com as grandes festas do terreiro. Além disso, as festas vão adquirindo, muitas vezes, um certo ar das festas profanas, dado pelo uso de bandeirinhas e balões coloridos para a decoração, ou ainda pela presença de um grande bolo confeitado, barris de chopp para acompanhar o ajeun, docinhos e até mesmo lembrancinhas com os símbolos dos orixás. Isto mostra a grande capacidade da festa (do candomblé) de abrigar todas as dimensões da vida dos filhos de santo, marcando os momentos da vida de um adepto para todo o grupo e ao mesmo tempo, sacralizando-os.

A festa de candomblé é, portanto, um elemento organizativo, que não só mostra publicamente tudo que o grupo é em termos de nação, estética, origens, conhecimento, riqueza, prosperidade, como também expressa toda a hierarquia construída através do passar do tempo no terreiro e o consequente conhecimento do ritual. É nas festas, também, que são travados alguns conhecimentos, onde são recrutados, muitas vezes, novos adeptos. É nas festas que os grupos de candomblé se visitam, reforçando ou afrouxando laços através de vínculos ou conflitos que também nelas são criados. É em função da festa que os membros de um terreiro se unem, se organizam, se ajudam e cotizam. É para trabalhar pela festa que eles organizam o tempo disponível durante o não-trabalho. Muitos fazem horas extras para comprar uma nova roupa para seu orixá, ou mesmo para si. Desse modo, temos que os dias, a semana, o ano e toda a passagem do tempo é organizada em termos da organização, produção e participação das festas, sejam elas sagradas ou profanas. No candomblé, tempo é conhecimento, é produção da festa, e festa é vida.

Essa frequente produção da festa e participação nela é o elemento que produz o gosto, do povo-de-santo, por outras esferas festivas da vida social, tais como as rodas-de-samba, afoxés, carnaval etc.. Para opovo-de-santo, que se espelha nos orixás, que vêm ao mundo apenas para dançar e festejar, o tempo de festa é sempre. Porque a vida, quando se tem saúde, alegria, amor, deve ser festejada. Não importa se o trabalhoéduro, se a vidaé dificil. Estes momentos situam-se fora da festa, fora da verdadeira "vida", que é a festa. E assim a cidade, para o povo-de-santo, é uma cidade boa, onde se conseguem os recursos para a festa e onde se vive buscando-a mais e mais, em diferentes momentos e lugares. $A$ vida é festa. $\mathrm{O}$ resto é exceção. Para o povo-de-santo, a alegria é que é a "prova dos nove".

*Rita de Cássia Amaral é antropóloga e atualmente estuda relações raciais no candomblé. Elaborou este artigo com baseem pesquisa financiada pela FAPESP.

\section{NOTAS}

1 - Para outros aspectos festivos da vida das classes mais pobresver MA GNANI, José Guilherne. Festa no Pedaço. Brasiliense, Såo Paulo 1984.

2- AMARAL, Rita de Cássia - Povo-de-Santo povo de festa-estudo antropológico do estilc le vida dos adeptos do candomblé paulista. pissertaçåo de Mestrado, USP, 1992.

3- PRANDI, Reginaldo - Os candomblés da cidade HUCITEC/EDUSP, Såo Paulo, 1991

4-NINA RODRIGUES, Raimundo-O animismo jetichista dos negros bahianos Ed. Civilizaçă Brasileira, Rio de Janeiro, 1935. 